\title{
Effects of a cognitive stimulation program on institutionalized older people
}

Efeitos de um programa de estimulação cognitiva em idosos institucionalizados Efectos de un programa de estimulación cognitiva en ancianos institucionalizados

Vítor Parola*iD; Adriana Coelho**iD; Hugo Neves***iD; Maria Almeida****iD; Isabel Gil ${ }^{* * * * * i D}$; Ana Mouro****** (D); João Apóstolo******* (iD)

\section{Abstract}

Background: The evidence suggests that cognitive stimulation in the elderly has positive results in cognition and depressive symptomatology.

Objective: To evaluate the effectiveness of a cognitive stimulation program in cognition and depressive symptomatology in institutionalized older people.

Methodology: Experimental study in a sample of 100 elderly individuals. The Portuguese versions of the Mini-Mental State Examination and the Geriatric Depression Scale-15 were applied to each one of the groups in the pre-test and post-test. The experimental group was submitted to 14 sessions of cognitive stimulation.

Results: The cognitive stimulation program improved cognition $(p<0.01)$, with no occurrence of statistically significant differences in the depressive symptomatology when comparing both groups $(p>0.05)$. From a clinical point of view, there was a reduction in depressive symptomatology $(p<0.05)$ in the experimental group, while the same is not true in the control group $(p>0.05)$.

Conclusion: The cognitive stimulation program significantly improved cognition, explaining $9.8 \%$ of identified variability. The results are encouraging, demonstrating that the program benefits institutionalized older people, thus contributing to the maintenance of their mental health.

Keywords: cognition; nursing; randomized controlled trial; aging; aged

\section{Resumo}

Enquadramento: A evidência sugere que a estimulação cognitiva nos idosos tem resultados positivos na cognição e na sintomatologia depressiva.

Objetivo: Avaliar a eficácia de um programa de estimulação cognitiva na cognição e sintomatologia depressiva em idosos institucionalizados.

Metodologia: Estudo experimental numa amostra de 100 idosos. A versão portuguesa da Mini-Mental State Examination e da Geriatric Depression Scale-15 foram aplicadas a cada um dos grupos no pré-teste e no pós-teste. O grupo experimental foi submetido a 14 sessóes de estimulação cognitiva.

Resultados: O programa de estimulaçáo cognitiva melhorou a cogniçâao $(p<0,01)$, não existindo diferenças estatisticamente significativas na sintomatologia depressiva quando se comparam ambos os grupos $(p>0,05)$. Do ponto de vista clínico, no grupo experimental verificou-se uma redução da sintomatologia depressiva $(p<0,05)$, sendo que o mesmo náo sucede no grupo de controlo $(p>0,05)$.

Conclusão: $\mathrm{O}$ programa de estimulação cognitiva melhorou significativamente a cognição, explicando 9,8\% da variabilidade identificada. Os resultados obtidos são encorajadores, demonstrando que o programa produz benefícios para idosos institucionalizados, contribuindo, assim, para a manutençáo da sua saúde mental.

Palavras-chave: cognição; enfermagem; ensaio clínico controlado aleatório; envelhecimento; idoso

*MSc., Doctoral Student in Nursing Sciences in Instituto de Ciências Biomédicas Abel Salazar: Invited Assistant, Nursing School of Coimbra, Health Sciences Research Unit: Nursing, 3046851, Coimbra, Portugal vitorparola @ esenfc pt]. [D https://orcid.org/0000-0002-0050-500 851, Coimbra, Portugal vitorparola @ esentc.pt]. D https://Orcid.org/0000-0002-0050-500and analvsis: writing of the article. Address for correspondence: Avenida Bissaya Barreto, Apatado 7001, 3046-851, Coimbra, Portugal.

**MSc., Doctoral Student in Nursing Sciences in Instituto de Ciências Biomédicas Abel Salazar Invited Adjunct Professor, Nursing School of Coimbra Health Sciences Research Unit: Nursin 3046-851. Coimbra Portugal [adriananevescoelho@ a Heanfc pt]. (D hes Research Unit: Nursing 630-851, Coimbra, Portugal [adrananevescoelho@esenf.pt].(1) https://orcid.org/0000-0002 analysis; article revision.

***MSc., Invited Assistant Professor, Health Sciences School - Polvtechnic Institute of Leiria 2411-901, Leiria, Portugal [hugoneves@gmail.com]. (D) https://orcid.org/0000-0002-6843-6228. Contribution to the article: methodology planning: study desion; data treatment and analysis; article revision.

Coordinating Professor, Nursing School of Coimbra, 3046-851, Coimbra, Portugal mlurdes $\alpha$ esenfc pt] https:// orcid org 0000-0002-4454-8743. Contribution to the article

methodological supervision; article revision.
$*$ ***** MSc., Assistant Professor, Nusing School of Coimbra, 3046-851, Coimbra, Portugal ligil@ esenf.pt]. (D) https://orcid.org/0000-0002-5387-8285. Contribution to the article: methodologi-

cal supervision, article revision.
$* * * * *$ Grad., Physical Therapist, Lar de Santo António, 7430-030. Aldeia da Mata, Portugal Ifisio@lardesantoantonio.com. (D) httns://orcid.org/0000-0002-9867-5051. Contribution to the article: methodology planning; data collection article revision

article: methodology planning; data collection; article revision. arch Unit: Nursing 3046-851. Coimbra [apostolo@esenfc.pt]. (D) https://orcid org/0000-0002 3050-4264. Contribution to the article: methodology planning. study design; methodologica supervision; data treatment and analysis; article revision.

\section{Resumen}

Marco contextual: La evidencia sugiere que la estimulación cognitiva en los ancianos tiene resultados positivos en la cognición y la sintomatología depresiva.

Objetivo: Evaluar la eficacia de un programa de estimulación cognitiva en la cognición y sintomatología depresiva en ancianos institucionalizados.

Metodología: Estudio experimental en una muestra de 100 ancianos. La versión portuguesa de la Mini-Mental State Examination y de la Geriatric Depression Scale-15 se aplicó a cada uno de los grupos en el pretest y en el postest. El grupo experimental se sometió a 14 sesiones de estimulación cognitiva.

Resultados: El programa de estimulación cognitiva mejoró la cognición $(p<0,01)$, y no se observaron diferencias estadísticamente significativas en la sintomatología depresiva al comparar ambos grupos $(p>0,05)$. Desde el punto de vista clínico, en el grupo experimental se verificó una reducción de la sintomatología depresiva $(p<0,05)$, pero no sucedió lo mismo en el grupo de control $(p>0,05)$.

Conclusión: El programa de estimulación cognitiva mejoró significativamente la cognición, lo que explica el 9,8\% de la variabilidad identificada. Los resultados obtenidos son esperanzadores, pues demuestran que el programa aporta beneficios a los ancianos institucionalizados, y contribuye a mantener su salud mental.

Palabras clave: cognición; enfermería; ensayo clínico controlado aleatorio; envejecimiento; anciano 


\section{Introduction}

Population ageing is a global phenomenon, especially visible in the Portuguese context. Portugal has an increasingly ageing age structure, and in 2080 there will be expectedly around 2.8 million people with 65 years or more (Instituto Nacional de Estatística, 2017), being one of the countries of the European Union with the highest percentage of seniors.

The ageing population has led to an increase in the prevalence of chronic degenerative diseases, particularly of neurocognitive disorders (NCDs). One estimates that in 2015, 46.8 million people around the world presented NCDs primary and that this number will increase exponentially an estimated 131.5 million in 2050 (Prince, Comas-Herrera, Knapp, Guerchet, \& Karagiannidou, 2016).

In 2004, there were approximately 56,535 older adults who were institutionalized in Portugal, representing $3.2 \%$ of the elderly. Subsequently, in 2011, this number increased to 91,202 , representing $4.5 \%$ of older people (Instituto Nacional de Estatística, 2017).

Thus, in our specific context, it has been noted, either through the implementation of other ongoing projects, either by lack manifested by the institutions in general and the elderly in particular, the need to create a program that delayed the effects of NCDs.

In this context, several studies have focused on the development, implementation and evaluation of the impact of cognitive stimulation (CS) in cognition and depressive symptomatology of institutionalized elderly, once that can promote the well-being in the elderly population. The depressive symptoms in seniors are associated with a cognitive and functional decline, which represents a risk factor for NCDs (Bunce, Batterham, Mackinnon, \& Christensen, 2012). This point of view is reinforced by Rosness, Barca, e Engedal (2010) when mentioning that elderly patients with depression have a higher risk of developing cognitive disorders and NCDs. According to Frade, Barbosa, Cardoso, \& Nunes (2015), the prevention of depression in the elderly must pass through the creation of activities that promote the so-called active ageing, as the mental activity and the socialization of the elderly. For this reason, it is of high relevance the nurse's role in early diagnosis, as well as in the implementation of therapeutic interventions to prevent or minimize the development of these clinical conditions.

In this sense, the program of cognitive stimulation - Make a Difference (PEC-FD) constitutes an intervention for the promotion of healthy aging, and represents a possibility to compensate for the cognitive deficits and depressive symptoms, allowing the elderly to remain active, independent and autonomous for as long as possible (Apóstolo, Cardoso, Rosa, \& Paúl, 2014; European Innovation Partnership on Active and Healthy Aging, 2016). For this reason, the objective of this study is to evaluate the effectiveness of a program of cognitive stimulation in cognition and depressive symptomatology in institutionalized seniors.

\section{Background}

The PEC-FD complies with the National Strategy for Active and Healthy Aging 2017-2025 and with the National Health Plan - Review and Extension to 2020, the Directorate General for Health (Direção-Geral da Saúde, 2017). In addition, it complies with the defined by the European Innovation Partnership on Active and Healthy Aging (EIP-AHA), since it is a preventive and highly beneficial approach for elderly people with a reduced financial cost (Pillar I), enabling them to stay socially active, autonomous, and independent for a more extended period of time (Pillar III; European Innovation Partnership on Active and Healthy Aging, 2016). CS is an intervention, usually in a social environment, that offers a sequence of enjoyable activities that encompass cognitive areas such as attention, language, reasoning, learning, memory, visual-spatial processing, and executive functions.

These activities, because they require logical thought, attention, and concentration, promote the increase of cerebral synaptic density, as this transmission network is responsible for brain dynamics and plasticity. Thus, in seniors with cognitive decline, CS presents itself as a promising intervention for the reduction of symptoms, offering benefits at the level of the interaction of participants and their communicational relations (Apóstolo, Cardoso et al., 2014; Middelstadt, Folkerts, Blawath, \& Kalbe, 
2016; Spector, Woods, \& Orrell, 2008).

Moreover, the CS intervention has a good cost-benefit ratio, since, as regards NCDs, the benefits in cognition are comparable to those obtained through medication (Spector et al., 2008). A systematic review with meta-analysis, which included 15 randomized controlled studies, found that CS can associate with improvements in the quality of life and the communication of older adults. However, there was no evidence of their effectiveness as regards depressive symptomatology (Woods, Aguirre, Spector, \& Orrell, 2012). In another systematic review (Jean, Bergeron, Thivierge, \& Simard, 2010), while analyzing the effectiveness of 15 cognitive stimulation programs in individuals with mild cognitive decline, significant improvements occurred after the intervention at the level of memory, quality of life, and humour. Scientific literature shows that CS should be an essential care component for seniors, as it allows to obtain gains in health (Apóstolo, Cardoso et al., 2014).

Nevertheless, existing studies present some limitations such as the small sample size and the fact the majority are implemented in the elderly population living in the community, which justifies the need to conduct a study on the impact of CS in cognition and depressive symptomatology of institutionalized seniors.

\section{Hypotheses}

Hypothesis 1 - The institutionalized seniors submitted to the PEC-FD manifest a more significant improvement in cognitive status than those not subjected to the program.

Hypothesis 2 - The institutionalized seniors undergoing the PEC-FD manifest a more significant improvement of depressive symptoms than those not submitted to the program.

\section{Methodology}

This is an experimental study with a random- ized controlled trial, pre- and post-test, and control group (CG).

Experimental group $(E G) t_{1} \times E t_{2} ; G C t_{1} x$ $\mathrm{CG} \mathrm{t}_{2}$

Target population - To ensure that the sample represented the Portuguese population, the evaluation focused on seniors of five residential structures for older adults, located in the central region of Portugal and Alentejo. The sample was composed of elderly individuals of both genders, with 65 or more years of age, residing in these institutions and who met the following inclusion criteria, as referred by the authors of the intervention (Apóstolo \& Cardoso, 2014): institutionalized seniors with a score of 10 or more on the Mini-Mental State Examination (MMSE) scale, in order to exclude an intense cognitive impairment; score higher than 20 in the Barthel Index, so as to exclude seniors with high levels of dependency; able to participate in group activities for 45-60 minutes; absence of significant sensory deficits and lack of agitation that makes the participation in group activities impossible during the time proposed for each session.

Randomization - Conducted in the five contexts of the implementation of the study. After applying the inclusion criteria, 100 subjects were selected. The allocation ratio in the EG or the CG was 1:1. For the randomization (True Random Number Generator) the webpage www.random.org was used. The diagram in Figure 1 shows the process of randomization of the subjects.

The statistical power analysis was based on a type I error rate of 0.05 , a power of 0.80 , an effect size of 0.35 - calculation performed taking into account previous studies (Apóstolo \& Cardoso, 2014; Apóstolo, Cardoso, et al., 2014) - and variance analysis (variance analyses [ANOVA]) with repeated-measures factors. This statistical power analysis determined a minimum size of 44 people for the sample. An independent researcher calculated the sample size using the computer program $\mathrm{G}^{*}$ Power 3 . 


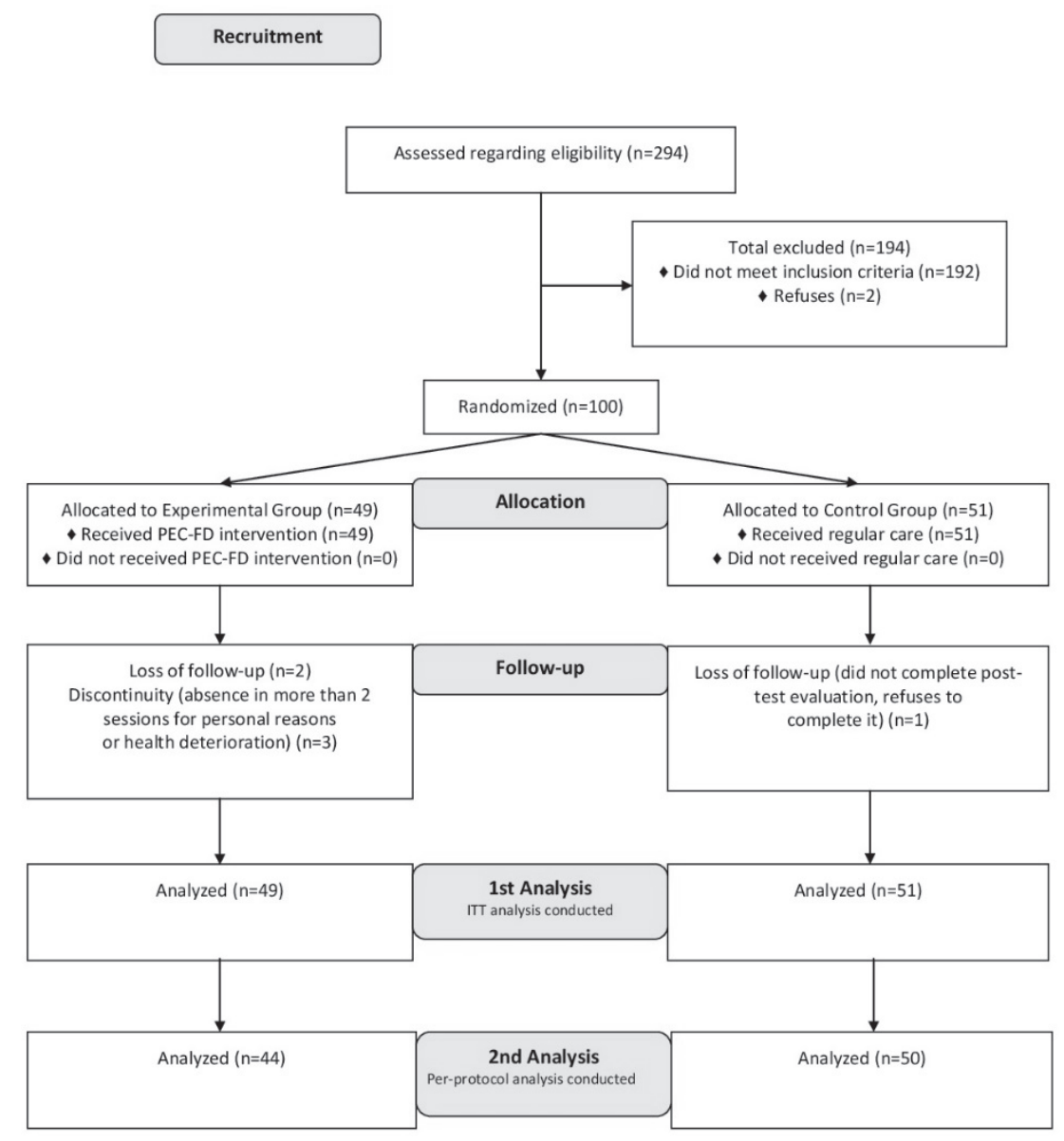

Figure 1. Diagram of the process of subjects' randomization.

\section{Instruments}

After obtaining the free and informed consent, evaluation tools of cognition and depressive symptomatology were applied in the pre-test $-\mathrm{t}_{1}$ and in the post-test $-\mathrm{t}_{2}$.

Cognition: The MMSE - Portuguese version - (Morgado, Rocha, Maruta, Guerreiro, \& Martins, 2009) was employed. The MMSE is one of the most frequently used instruments in the screening of cognitive decline in epidemiological studies, as well as the overall assessment of cognitive functions (Morgado et al., 2009).

Depressive symptomatology: The Geriatric Depression Scale (GDS-15) - Portuguese version - (Apóstolo, Loureiro, et al., 2014) was employed. This scale of hetero-assessment presents two alternative responses, regarding how the elderly felt during the last two weeks. The GDS15 proved to be well accepted by seniors, as it did not usually require additional explanations. A team of different assistant researchers, previously trained in the application of these instruments, applied the MMSE and GDS-15 instruments to avoid the bias of detection. Therefore, the intervention was implemented and evaluated by different assistant researchers (members of the multidisciplinary team).

\section{Implemented intervention}

The PEC-FD, Portuguese version of Making a Difference: An Evidence-based Group Program to Offer Cognitive Stimulation Therapy to People with Dementia was used as an intervention, being translated and adapted to the Portuguese cultural context by Apóstolo and Cardoso (2014).

The PEC-FD intervention consisted of two weekly sessions for seven weeks in the year 2016. Each session of the program took be- 
tween 45 to 60 minutes. There was no intervention in the CG in addition to those previously developed by the Institutions.

\section{Statistical analysis}

According to the Central Limit Theorem, one assumes that for samples exceeding 30 individuals, as is the case of this study, the use of parametric methods is justified. Thus, for this study, the authors opted for the parametric statistical tests.

The hypothesis test used parametric tests, namely the Student's $t$-test and the repeated-measures analysis of variance (ANOVA). A decision was made to conduct an intention-to-treat (ITT) analysis because some subjects did not complete the post-intervention evaluation. Therefore, the presented results will be obtained taking into account the sample's totality $(n=100$, which includes the ITT cases) and the per-protocol sample that excludes the ITT cases $(n=94)$, which also allows understanding if they have a significant influence on the results.

For the statistical treatment of data the IBM SPSS Statistics program, version 20.0, was used. A value of $p \leq 0.05$ was considered to indicate statistical significance.

\section{Ethical procedures}

This study was approved by the institutions and by the Ethics Committee of the Health Sciences Research Unit: Nursing of the Nursing School of Coimbra (P12-11/2010). The underlying ethical principles were complied with in each phase of the study, having developed all procedures respecting anonymity, confidentiality, and informed consent of the participants.

\section{Results}

\section{Sociodemographic and clinical characteri- zation of elderly people}

The sample is composed of 100 people, whose age ranges between 65 and 100 years old $(M=84.45$; $S D=7.497)$. The sample includes predominantly female subjects (75\%). As regards qualifications, the majority of respondents $(60 \%)$ studied for 3 to 6 years. The EG and CG did not differ significantly regarding gender, education, age, cognition, and depressive symptomatology. The baseline characteristics of the sample and the comparisons between the groups concerning the sociodemographic and clinical data of the subjects are shown in Table 1.

Table 1

Baseline characteristics of the sample and the comparisons between the groups concerning the sociodemographic and clinical data of the subjects

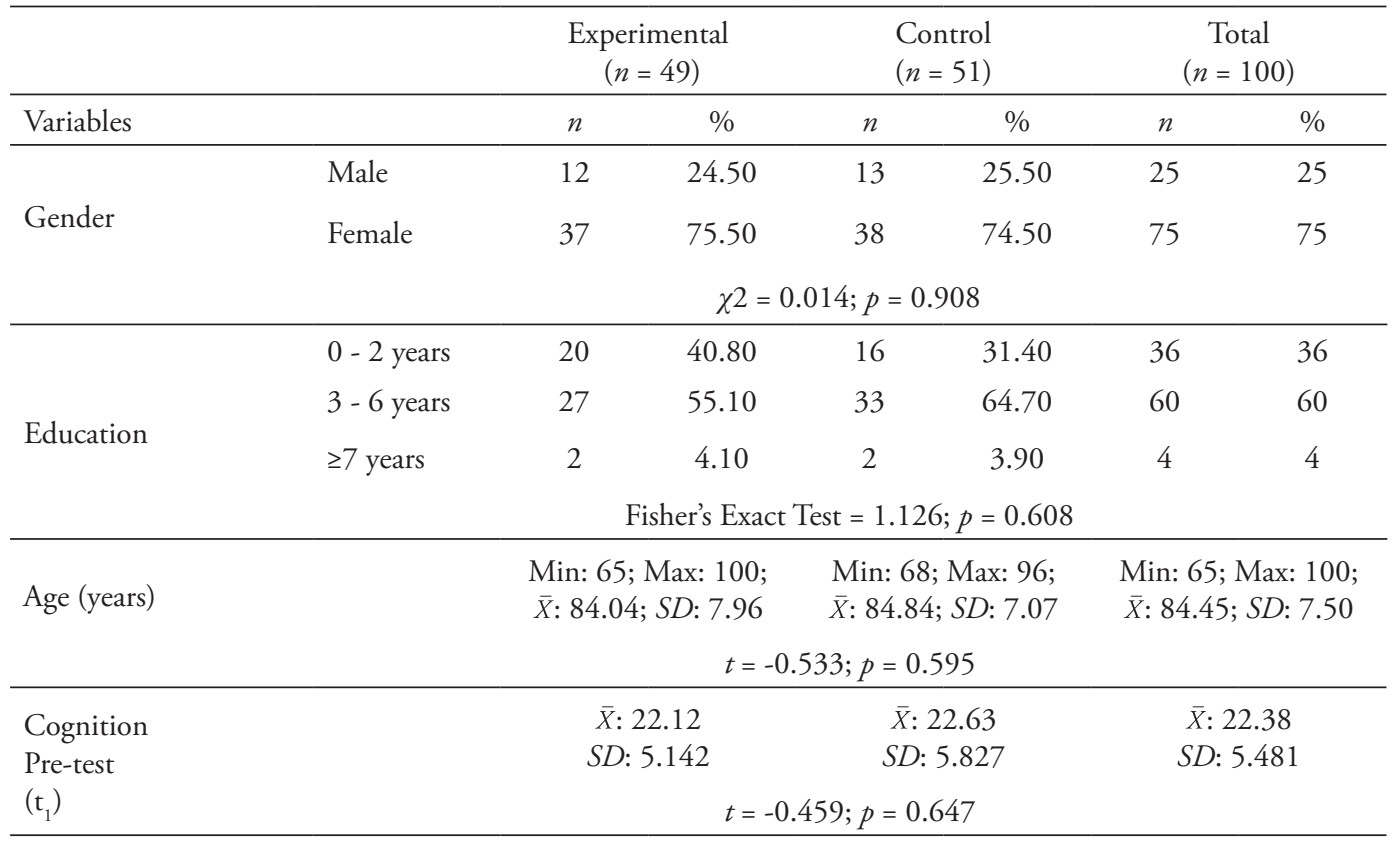




\begin{tabular}{lccc}
\hline Depressive & $\bar{X}: 6.78$ & $\bar{X}: 5.90$ & $\bar{X}: 6.33$ \\
symptomatology & $S D: 3.907$ & $S D: 3.442$ & $S D: 3.685$ \\
Pre-test & & $t=1.188 ; p=0.238$ & \\
$\left(\mathrm{t}_{1}\right)$ & & \\
\hline
\end{tabular}

Note. $n=$ Number of individuals in the sample; $\chi 2=$ Chi-squared test; Min = minimum; Max = Maximum; = Mean; $S D=$ Standard deviation; $t=$ Student's $t$-test; $p=$ Level of significance; $\mathrm{t}_{1}=$ Pre-test.

The initial assessment (pre-test), relating to the cognitive status and depressive symptoms in seniors $(n=100)$, showed that $55.1 \%$ of the EG and $47.1 \%$ of the CG were marked as having cognitive impairment; and $61.2 \%$ of the EG and $51.0 \%$ of the CG were marked as having depressive disorder.

As regards the assessment data of the effect of the PEC-FD intervention developed with the EG seniors, in comparison to the CG, they are presented in Table 2, for the sample which included the ITT cases $(n=100)$.

Table 3 presents the data relating to the per-protocol sample when excluding the ITT cases $(n=94)$.

The occurred results reveal a positive evolution $(\bar{X}=2.04)$ in cognitive status, when the PEC-FD was implemented in the EG seniors. The same did not occur in the CG, which manifested a slight loss. Using Student's $t$-test for paired samples, it was found that the EG evolution is statistically significant $(t=4.40$; 95\% CI, $1.13-2.95 ; p<0.001$ ), although the same is not true in the CG. When one compares this difference between the groups, the result of the repeated-measures analysis of variance indicates that the difference is statistically significant $(p<0.01)$. Thus, the EG, compared to the CG, achieved an improvement in cognition $(\bar{X}=+2.04$ vs. -0.19 ; $F=10.62 ; p<0.01$; partial eta-squared $\left(\eta^{2} p\right)=$ 0.098 ; power $=0.897$ ). This result shows that the cognitive stimulation is effective in improving cognition, which explains $9.8 \%$ of the variability.

Regarding depressive symptomatology, the results reveal a positive evolution $(\bar{X}=0.86)$ in the EG, and that a slight improvement occurred in the CG $(\bar{X}=0.57)$. Using Student's $t$-test for paired samples, it was found that the evolution of the EG is statistically significant $(t=-1.90 ; 95 \% \mathrm{CI},-1.76-0.05 ; p<0.05)$, although the same is not true in the CG. Concerning this aspect, it should be noted that, although the evolution in the EG from $t_{1}$ to $t_{2}$ is statistically significant within the group, as it was previously mentioned, when comparing the groups, it is not statistically significant $\left(p>0.05\right.$; partial eta-squared $\left(\eta^{2} p\right)=0.003$; power $=0.078)$.

Table 2

Evolution of the EG and CG relating to the cognitive status and depressive symptomatology in seniors, including ITT

\begin{tabular}{lccccccccccc}
\hline & & \multicolumn{1}{c}{$\mathrm{t}_{1}$} & \multicolumn{2}{c}{$\begin{array}{c}\mathrm{t}_{2} \\
(\text { post-test })\end{array}$} & $\begin{array}{c}\text { Student's } t \text {-test } \\
\text { for paired } \\
\text { samples }\left(\mathrm{t}_{2}-\mathrm{t}_{1}\right)\end{array}$ & $\begin{array}{c}\text { Evolution } \\
\left(\mathrm{t}_{2}-\mathrm{t}_{1}\right)\end{array}$ & \multicolumn{2}{c}{$\begin{array}{c}\text { Repeated } \\
\text { measures }\end{array}$} \\
\hline Outcomes & Groups & $\bar{X}$ & $S D$ & $\bar{X}$ & $S D$ & $t$ & $p$ & $\bar{X}$ & $S D$ & $F$ & $p$ \\
\hline $\begin{array}{l}\text { Cognitive } \\
\text { status } \\
(n=100)\end{array}$ & $\begin{array}{c}\text { Experimental } \\
(n=49)\end{array}$ & 22.12 & 5.14 & 24.16 & 4.79 & 4.499 & 0.000 & 2.04 & 3.175 & & \\
\hline $\begin{array}{l}\text { Control } \\
(n=51)\end{array}$ & 22.63 & 5.83 & 22.43 & 5.97 & -0.383 & 0.352 & -0.19 & 3.661 & & \\
\hline $\begin{array}{l}\text { Depressive } \\
\text { symptoma- } \\
\text { tology } \\
(n=100)\end{array}$ & $\begin{array}{c}\text { Experimental } \\
(n=49)\end{array}$ & 6.78 & 3.91 & 5.92 & 3.99 & -1.897 & 0.032 & -0.86 & 3.162 & & \\
\hline $\begin{array}{l}\text { Control } \\
(n=51)\end{array}$ & 5.90 & 3.44 & 5.33 & 3.62 & -1.561 & 0.062 & -0.57 & 2.602 & & \\
\hline
\end{tabular}

Note. $n=$ Number of individuals in the sample; $\bar{X}=$ Mean; $S D=$ Standard deviation; $t=$ Student's $t$-test; $p=$ Level of significance; $F=F$ statistics of ANOVA; $\mathrm{t}_{1}=$ Pre-test; $\mathrm{t}_{2}=$ Post-test. 
The observed results, excluding the ITT cases, reveal positive development in cognitive status $(\bar{X}=2.27)$ in the EG. However, this did not occur with the CG, which manifested a slight loss. It was also found that the evolution in the EG continues to be statistically significant $(t=4.61 ; 95 \% \mathrm{CI}, 1.28-3.27 ; p<0.001)$, though not statistically significant in the CG. When comparing this difference between the groups, it reveals statistical significance again $(p<0.01)$. Thus, the EG, compared to the CG, achieved an improvement in cognition ( $\bar{X}=+2.27$ vs. $-0.20 ; F=11.64 ; p<0.01$; partial square $\left(\eta^{2} p\right)=0.112$; power $\left.=0.922\right)$. This result shows that cognitive stimulation is effective in improving cognition, what explains $11.2 \%$ of the variability.

Concerning depressive symptomatology, a positive evolution $(\bar{X}=0.95)$ occurred, slightly higher when compared with cases that included the ITT cases. The same happens in the CG, where there is a slight improvement. It was found again that the evolution is statistically significant in the EG $(t=-1.90$; 95\% CI, $-1.97-0.06 ; p<0.05$ ), while it is not in the CG. The results indicate once again that, when comparing the differences found between the groups, it is not statistically significant $\left(p>0.05\right.$; partial eta-squared $\left(\eta^{2} p\right)=$ 0.004 ; power $=0.093)$.

Table 3

Evolution of the EG and CG relating to the cognitive status and depressive symptomatology in seniors, excluding ITT

\begin{tabular}{|c|c|c|c|c|c|c|c|c|c|c|c|}
\hline \multirow[b]{2}{*}{ Outcomes } & \multirow[b]{2}{*}{ Groups } & \multicolumn{2}{|c|}{$\begin{array}{c}\mathrm{t}_{1} \\
\text { (pre-test) }\end{array}$} & \multicolumn{2}{|c|}{$\begin{array}{c}\mathrm{t}_{2} \\
\text { (post-test) }\end{array}$} & \multicolumn{2}{|c|}{$\begin{array}{l}\text { Student's } t \text {-test } \\
\text { for paired } \\
\text { samples }\left(t_{2}-t_{1}\right)\end{array}$} & \multicolumn{2}{|c|}{$\begin{array}{l}\text { Evolution } \\
\qquad\left(t_{2}-t_{1}\right)\end{array}$} & \multicolumn{2}{|c|}{$\begin{array}{l}\text { Repeated } \\
\text { measures }\end{array}$} \\
\hline & & $\bar{X}$ & $S D$ & $\bar{X}$ & $S D$ & $t$ & $p$ & $\bar{X}$ & $S D$ & $F$ & $p$ \\
\hline \multirow{2}{*}{$\begin{array}{l}\text { Cognitive status } \\
(n=94)\end{array}$} & $\begin{array}{l}\text { Experimental } \\
\qquad(n=44)\end{array}$ & 22.34 & 5.18 & 24.61 & 4.62 & 4.606 & 0.000 & 2.27 & 3.27 & \multirow{2}{*}{11.64} & \multirow{2}{*}{0.001} \\
\hline & $\begin{array}{l}\text { Control } \\
(n=50)\end{array}$ & 22.80 & 5.75 & 22.60 & 5.91 & -0.382 & 0.352 & -0.20 & 3.70 & & \\
\hline \multirow{2}{*}{$\begin{array}{l}\text { Depressive } \\
\text { symptomatology } \\
(n=94)\end{array}$} & $\begin{array}{l}\text { Experimental } \\
\qquad(n=44)\end{array}$ & 6.43 & 3.76 & 5.48 & 3.76 & -1.903 & 0.032 & -0.95 & 3.33 & \multirow{2}{*}{0.37} & \multirow{2}{*}{0.272} \\
\hline & $\begin{array}{l}\text { Control } \\
(n=50)\end{array}$ & 5.88 & 3.47 & 5.30 & 3.65 & -1.561 & 0.062 & -0.58 & 2.63 & & \\
\hline
\end{tabular}

Note. $n=$ Number of individuals in the sample; $\bar{X}=$ Mean; $\mathrm{SD}=$ Standard deviation; $\mathrm{t}=$ Student's $\mathrm{t}$-test; $\mathrm{p}=$ Level of significance; $\mathrm{F}=\mathrm{F}$ statistics of ANOVA; $\mathrm{t}_{1}=$ Pre-test; $\mathrm{t}_{2}=$ Post-test.

After having shown the results that allow to affirm that on average the seniors of the EG manifest an improvement in cognitive status of approximately 2 points, regarding the instrument of assessment of cognitive state - MMSE -, which observed that the seniors of the EG manifest on average an improvement in the depressive symptomatology of roughly 1 point, and that the seniors of the CG show on average an improvement in the depressive symptomatology of slightly more than 0.5 points, it is essential to ascertain the number of cases that evolved positively, negatively, or that did not show any changes, allowing a clinical analysis of the results.
Therefore, as regards the clinical evaluation of the results at the level of cognition, in the EG $27(55.1 \%)$ of the elderly patients improved, 6 (12.3\%) declined, and $16(32.6 \%)$ maintained their status, while in the CG $20(39.2 \%)$ of the elderly patients improved, 21 (41.2\%) declined, and $10(19.6 \%)$ maintained their status. The data analysis excluding the ITT cases show that, in the EG, $27(61.4 \%)$ of the elderly patients improved, 6 (13.6\%) declined, and 11 (25\%) maintained their status, while in the CG 20 $(40.0 \%)$ of the elderly patients improved, 21 (42.0\%) declined, and $9(18.0 \%)$ maintained their status.

Concerning depressive symptomatology, in 
the GE, 27 (55.1\%) of the elderly patients improved, 12 (24.5\%) declined, and 10 (20.4\%) maintained their status, while in the CG 23 (45.1\%) of the elderly patients improved, 18 $(35.1 \%)$ declined, and $10(19.6 \%)$ maintained their status. The data analysis excluding the ITT cases show that, in the GE, $27(61.4 \%)$ of the elderly patients improved, 12 (27.3\%) declined, and $5(11.3 \%)$ maintained their status, while in the CG $23(46.0 \%)$ of the elderly patients improved, 18 (36.0\%) declined, and 9 (18.0\%) maintained their status.

\section{Discussion}

Taking into account the objective and the hypotheses of the study, the results suggest that CS is efficient and statistically significant in the cognitive status of seniors, explaining $9.8 \%$ and $11.2 \%$ of the variation, including or excluding the ITT cases respectively, who is considered a moderate improvement with great clinical relevance. The analysis of the cases' evolution allows noting that the seniors submitted to the PEC-FD manifest an improvement of their cognitive status, with $55.1 \%$ (including ITT) and $61.4 \%$ (excluding ITT) having evolved positively, when comparing to the CG in which this evolution only occurred in $39.2 \%$ and $40.0 \%$ respectively. One can also note a large number of adverse evolutions that exist in the CG (41.2\%) including ITT and $42.0 \%$ per protocol, that is, excluding ITT - when comparing to the group submitted to the PEC-FD $-12.3 \%$ and $13.6 \%$, respectively.

The obtained results are comparable to other studies, namely those of Spector et al. (2003), in which the implementation of the PEC-FD showed significant improvements at the level of cognition, and those of Spector et al. (2008), where the application of the same program in elderly patients with mild to moderate NCDs showed significant benefits in cognition and quality of life.

Other studies performed in Portugal that used the same PEC-FD in seniors have also proved to be effective. The experimental study developed by Apóstolo, Cardoso, Marta, \& Amaral (2011), which applied the PEC-FD in seniors residing in the community and demonstrated positive effects on cognition, stands out. A qua- si-experimental study, carried out with seniors living in institutions, also noted the positive impact of the PEC-FD in cognition (Apóstolo, Cardoso et al., 2014).

The results of this study do not provide evidence that sustains the statistically significant effect of the PEC-FD in depressive symptomatology, when comparing the EG with the CG ( $p$ $>0.05)$. Nevertheless, it must be noted that, from a clinical point of view, 27 of the elderly of the EG, compared to 23 in the CG, evolved positively. Another relevant aspect is that, from the pre-test $\left(t_{1}\right)$ to the post-test $\left(t_{2}\right)$, only in the EG (including and excluding the ITT cases) there was a statistically significant improvement $(p<0.05)$, revealing the benefits of the PECFD in depressive symptomatology. However, as previously mentioned, when comparing these results with the CG, they are not statistically significant.

The scientific evidence concerning this theme shows some inconsistency about the effect of CS on depressive symptomatology. In the research conducted by Spector et al. (2003), there was a lack of impact of CS on depressive symptomatology in the elderly. However, the study developed by Chariglione and Janczura (2013), in a sample composed of 21 seniors submitted to a program that includes different processes of cognitive stimulation, verified improvement in the depressive symptomatology and cognition in literate older adults.

In relation to the studies developed in Portugal that used the same PEC-FD in seniors, it was found once again that they are not conclusive concerning the effect of CS on depressive symptomatology, because while one of the studies shows that there are statistically significant differences (Apóstolo, Cardoso, Paúl, Rodrigues, \& Macedo, 2016), two other studies showed no statistically significant difference (Apóstolo, Cardoso, et al., 2014; Apóstolo et al., 2011). Although the results related to depressive symptomatology are not conclusive, they should be submitted to a careful analysis and consideration, because, for instance, in seniors with NCDs, lower scores on depressive symptomatology mean a higher probability of improvement in cognition and quality of life (Middelstadt et al., 2016). Thus, these results should not be underestimated, since a result can be statistically non-significant, but be clinically 
relevant (Loureiro \& Gameiro, 2011).

Limitations: The loss of six elements of the sample, particularly in the experimental group, meant that the analysis of the results had to be conducted twice, firstly excluding the cases that lacked data for a correct analysis, secondly including these cases through the use of the ITT procedure. This means that all elderly patients who were included in the study and randomly allocated were included in the analysis. Their data were analyzed in the randomized groups and concluded that the inclusion occurs regardless of the deviations that occurred after randomization (losses during the PEC-FD, non-fulfilment of the number of PEC-FD sessions, refusal). The ITT analysis preserves the prognostic balance generated by the original random treatment allocation. The completion of this procedure brings a more reliable estimate of the actual effectiveness of the PEC-FD, replicating what happens in the real world. When the ITT and per-protocol analyses arrive at the same conclusions, which occurred in this study, the confidence in the results of the study increases.

Finally, other variables such as the functional status and quality of life could have been included, so future studies should consider them.

\section{Conclusion}

The results of this study corroborate the results of studies of national and international context, where it is noted that the PEC-FD affects the improvement of the cognitive health of older adults. Therefore, the PEC-FD promotes the maintenance of the cognitive status of seniors, delaying the onset of dementia.

Although it has not been proven that CS has a positive and statistically significant effect on depressive symptomatology, both in cases including ITT and per-protocol, 55.1\% and $61.4 \%$, respectively, seniors submitted to the PEC-FD evolved positively, which shows the importance to carry out further studies in this area. This study corroborated results previously observed in the scientific literature, however showing the possibility of seniors benefitting in cognitive and emotional areas, using PEC. Despite the limitations above, the results of this study can contribute to the development of new lines of research in this context, enabling the emerging knowledge to have a direct impact on clinical practice.

The improvement or stabilization of cognitive functions and depressive symptomatology may be regarded as significant gains in health. As such, the main consequence of the practice of this study is that CS must be increasingly taken into consideration for inclusion in the intervention plans of nurses to seniors so that it contributes to the preservation of their cognitive and emotional capacity. As regards the institutions where CS is implemented, the consequences focus on the fact that it is a structured program with an available and easy-to-apply protocol and has an excellent cost-benefit ratio, thus inciting to change and improvement of clinical practice by the institutions. Regarding health professionals, its implementation has favored a closer relationship between the professional and the senior, resulting in a more in-depth knowledge of the elderly patient.

In summary, the results are encouraging and suggest that the therapeutic intervention of nursing, using cognitive stimulation, may constitute a facilitating element of transition processes of seniors with cognitive decline and depression, improving their response pattern.

\section{Acknowledgements}

The authors acknowledge the support of the Health Sciences Research Unit: Nursing (UICISA: E), the Nursing School of Coimbra (ESEnfC).

\section{References}

Apóstolo, J., \& Cardoso, D. (2014). Estimulação cognitiva em idosos-síntese da evidência e intervenção. In L. Loureiro (Coord.), Literacia em saúde mental: Capacitar as pessoas e as comunidades para agir (pp. 157-183). Coimbra, Portugal: Escola Superior de Enfermagem de Coimbra/Unidade de Investigação em Ciências da Saúde: Enfermagem..

Apóstolo, J., Cardoso, D. F., Paúl, C., Rodrigues, M. A., \& Macedo, M. S. (2016). Efectos de la estimulación cognitiva sobre las personas mayores en el ámbito comunitario. Enfermería Clínica, 26(2), 111-120. doi: 10.1016/j.enfcli.2015.07.008

Apóstolo, J., Cardoso, D. F., Rosa, A. I., \& Paúl, C. (2014). The effect of cognitive stimulation on nursing 
home elders: A randomized controlled trial. Journal of Nursing Scholarship, 46(3), 157-166. doi: 10.1111/ jnu. 12072

Apóstolo, J., Cardoso, D., Marta, L., \& Amaral, T. (2011). Efeito da estimulação cognitiva em idosos. Revista de Enfermagem Referência, 3(5), 193-201. doi: 10.12707/RIII11104

Apóstolo, J., Loureiro, L., Reis, I., Silva, I., Cardoso, D., \& Sfectcu, R. (2014). Contribuição para a adaptação da Geriatric Depression Scale -15 para a língua portuguesa. Revista de Enfermagem Referência, 4(3), 65-73. doi: 10.12707/RIV14033

Bunce, D., Batterham, P. J., Mackinnon, A. J., \& Christensen, H. (2012). Depression, anxiety and cognition in community-dwelling adults aged 70 years and over. Journal of Psychiatric Research, 46(12), 1662-1666. doi: 10.1016/j.jpsychires.2012.08.023

Chariglione, I. P., \& Janczura, G. A. (2013). Contribuiçôes de um treino cognitivo para a memória de idosos institucionalizados. Psico-USF, 18(1), 13-22.

Direção-Geral da Saúde. (2017). Estratégia nacional para o envelhecimento ativo e saudável 2017-2025.

European Innovation Partnership on Active and Healthy Ageing. (2016). Action Group A3 renovated action plan 2016-2018. Retrieved from https://ec.europa. eu/eip/ageing/sites/eipaha/files/library/renovated_action_plan_2016-2018_ag_a3.pdf

Frade, J., Barbosa, P., Cardoso, S., \& Nunes, C. (2015). Depression in the elderly: Symptoms in institutionalised and non-institutionalised individuals. Revista de Enfermagem Referência, 4(4), 41-49. doi: 10.12707/ RIV14030

Instituto Nacional de Estatística. (2017). Projeçōes de população residente 2015-2080. Lisboa, Portugal: Autor.

Jean, L., Bergeron, M.-È., Thivierge, S., \& Simard, M. (2010). Cognitive intervention programs for individuals with mild cognitive impairment: Systematic review of the literature. The American Journal of Geriatric Psychiatry, 18(4), 281-296. doi: 10.1097/
JGP.0b013e3181c37ce9

Loureiro, L., \& Gameiro, M. (2011). Interpretação crítica dos resultados estatísticos: Para lá da significância estatística. Revista de Enfermagem Referência, 3(3), 151-162. doi: 10.12707/RIII1009

Middelstadt, J., Folkerts, A. K., Blawath, S., \& Kalbe, E. (2016). Cognitive stimulation for people with dementia in long-term care facilities: Baseline cognitive level predicts cognitive gains, moderated by depression. Journal of Alzheimer's Disease, 54(1), 253-268. doi: 10.3233/JAD-160181

Morgado, J., Rocha, C. S., Maruta, C., Guerreiro, M., \& Martins, I. P. (2009). New normative values of Mini-Mental State Examination. Sinapse, 9(2), 10-16.

Prince, M., Comas-Herrera, M. A., Knapp, M., Guerchet, M., \& Karagiannidou, M. M. (2016). World Alzheimer Report 2016: Improving healthcare for people living with dementia: Coverage, quality and costs now and in the future. Retrieved from https://www.alz.co.uk/ research/WorldAlzheimerReport2016.pdf

Rosness, T. A., Barca, M. L., \& Engedal, K. (2010). Occurrence of depression and its correlates in early onset dementia patients. International Journal of Geriatric Psychiatry, 25(7), 704-711. doi: 10.1002/gps.2411 Spector, A., Thorgrimsen, L., Woods, B., Royan, L., Davies, S., Butterworth, M., \& Orrell, M. (2003). Efficacy of an evidence-based cognitive stimulation therapy programme for people with dementia: Randomised controlled trial. The British Journal of Psychiatry, 183(3), 248-254. doi: 10.1192/bjp.183.3.248

Spector, A., Woods, B., \& Orrell, M. (2008). Cognitive stimulation for the treatment of Alzheimer's disease. Expert Review of Neurotherapeutics, 8(5), 751-757. doi: 10.1586/14737175.8.5.751

Woods, B., Aguirre, E., Spector, A. E., \& Orrell, M. (2012). Cognitive stimulation to improve cognitive functioning in people with dementia. The Cochrane Database of Systematic Reviews, 15(2), CD005562. 